Research Article

\title{
Production and Pricing Strategies of Energy-Saving Products in the Presence of Duopolistic Manufacturers
}

\author{
Xuefeng Xia $\mathbb{D},{ }^{1}$ Zhenkai Lou $\mathbb{D},{ }^{2}$ and Xiaozhen Dai $\mathbb{D}^{3}$ \\ ${ }^{1}$ School of Economics and Management, Beijing University of Posts and Telecommunications, Beijing, China \\ ${ }^{2}$ School of Management and Economics, Beijing Institute of Technology, Beijing, China \\ ${ }^{3}$ School of Management, Wenzhou Business College, Zhejiang, China \\ Correspondence should be addressed to Xiaozhen Dai; 18810788027@139.com
}

Received 31 January 2020; Accepted 1 July 2020; Published 18 July 2020

Academic Editor: Zhiyun Lin

Copyright (C) 2020 Xuefeng Xia et al. This is an open access article distributed under the Creative Commons Attribution License, which permits unrestricted use, distribution, and reproduction in any medium, provided the original work is properly cited.

This paper considers optimal production and pricing strategies of energy-saving products in the presence of duopolistic manufacturers. First, we analyze the free competition case by a Bertrand game. A sufficient condition for guaranteeing the existence and the uniqueness of the equilibrium solution is proposed. The change rate of the benefit function of environment with regard to purchasing preference proportions is examined. Second, we investigate the case in the presence of energy-saving incentive. A two-layer decision model is constructed by considering the decision order of each participant. Optimal strategies between the two cases are compared. We provide theoretical foundations for the government to formulate policies of energysaving incentive under a financial budget constraint. Finally, a numerical example is presented to verify the obtained conclusions and make some supplements.

\section{Introduction}

Environmental consciousness has become increasingly important in everyday life and business practice [1]. Raising the consumer's demand for environmentally friendlier products with lesser harmful environmental effects is an important measure to protect the environment and save energies [2]. However, both manufactures and consumers prefer old-fashioned production because of its low cost [3]. Hence, governments introduce environmentally friendly regulations so as to enhance the positivity of both manufactures and consumers for energy-saving products [4]. In recent years, because of the high practicability, energysaving policies attract much attention. In industrialized countries such as China, energy-saving policies can potentially create significant economic, environmental, and social welfare benefits in the production and manufacturing sectors [5].

In recent years, a growing body of literature focuses on production and pricing strategies of energy-saving products in green supply chains. Swami and Shah [1] addressed some interesting questions such as the extent of effort in greening of operations by manufacturer or retailer, level of cooperation between the two parties, and how to coordinate their operations in a supply chain. Zhang et al. [6] investigated energy efficiency level and pricing policies in a single manufacturer-retailer setup, in which the production cost is affected by both cost learning and operational inefficiency effects. Arda [7] investigated the impact of emissions taxes on the optimal production and pricing decisions of a manufacturer who could remanufacture its product. Li et al. [8] considered a dual-channel green supply chain and discussed the pricing and greening policies for both centralized and decentralized situations by adopting the Stackelberg game. Similar to $\mathrm{Li}$, Hafezalkotob [9] also analyzed the competition and cooperation issues of energy-saving products; the difference is that he concerned two green supply chains. Song and Gao [10] focused on different revenue-sharing contracts of the whole green supply chain and compared the results of the common centralized model and the decentralized decision model. 
Energy-saving policies and subsidies of governments also attract much attention. In practice, government subsidies always play a crucial role in pricing and the choice of performance levels of energy-saving products $[11,12]$. For example, in China, the energy-saving subsidies have significantly promoted the production and sales of energy-saving electric appliances and new energy automobiles. Hong et al. [13] analyzed the impact of alternate schemes of government subsidies on the equilibrium amount, subsidy effectiveness, and subsidy elasticity. Hafezalkotob [14] compared six different policies in priceenergy saving and used these policies to study the two structures of centralized and decentralized green supply chains. Similarly, Javadi et al. [15] discussed government intervention policies of energy saving, revenue seeking, social welfare, and sustainable development in a dualchannel supply chain. Safarzadeh and Rasti-Barzoki [16] studied a sustainable supply chain which involves an energy-saving manufacturer, inefficient manufacturer, and energy supplier and constructed a multistage game model under government policies of tax deduction and subsidy scheme. More recently, Lou et al. [17] considered issues involving green subsidies of government and optimal decisions of a manufacture and dual-channel retailers in a two-echelon dual-channel supply chain and proposed sufficient and necessary conditions for guaranteeing the two supply chains run normally.

Our study is motivated by the abovementioned literature. Despite the plentiful related research, little focuses on two duopolistic manufacturers direct sell substitutable products. In reality, duopolistic market is widespread in many walks (e.g., $[16,18,19])$. Our research fills this gap by dealing with the Bertrand game between the two manufacturers who produce and sell energy-saving products. According to whether the government offers energy-saving subsidies, we develop two Bertrand game models. In addition to concerning the revenue of the two manufacturers, we also examine the environmental benefit. Our research yields some significant results: firstly, a sufficient condition for guaranteeing the existence and the uniqueness of the equilibrium solution of the two models is drawn; secondly, the change rate of the benefit function of environment with regard to purchasing preference proportions is examined; thirdly, it is shown that both sales prices and energy-saving levels of the two manufacturers are higher in the model with energy-saving subsidies; finally, theoretical foundations for the government to make policies of energy-saving incentive under the financial budget constraint are analyzed.

The remainder of this paper is organized as follows: necessary notations and assumptions as well as objective functions are given in Section 2; Section 3 conducts a Bertrand game to examine how the two manufacturers make decisions on the prices and on the energy-saving levels without energy-saving subsidies; the competition case in which the government provides subsidies for the energysaving production is discussed in Section 4; Section 5 presents a numerical illustration to make some supplements; Section 6 summarizes the whole paper.

\section{Notations and Assumptions}

In practice, many large manufacturers have their direct sales stores. This paper considers the competition and cooperation of duopolistic manufacturers when selling substitutable and energy-saving products by the direct sales model. Both of the two manufacturers aim to maximize their revenue in a given sales period.

The notations used in the following discussion are given as follows:

(i) $a$ is the potential product demands of the market for this type of product.

(ii) $\lambda$ is the purchasing preference proportion for manufacturer $\mathrm{A}$; thus, $1-\lambda$ measures the purchasing preference proportion for manufacturer B. Clearly, $0<\lambda<1$.

(iii) $\delta$ is the marginal demand with respect to the sales price, $\delta>0$.

(iv) $\theta$ is the demand shift between the two channels with respect to the price, $\theta>0$.

(v) $\alpha$ is the marginal demand with respect to the energy-saving level, $\alpha>0$.

(vi) $\beta$ is the demand shift between the two channels with respect to the energy-saving level, $\beta>0$.

(vii) $\varphi$ is the fixed cost of a manufacturer related to the energy-saving level, $\varphi>0$.

(viii) $\tau_{1}$ is the energy-saving level of manufacturer $\mathrm{A}$, $\tau_{1}>0$.

(ix) $p_{1}$ is the sales price determined by manufacturer $\mathrm{A}$.

(x) $\tau_{2}$ is the energy-saving level of manufacturer $\mathrm{B}$, $\tau_{2}>0$.

(xi) $p_{2}$ is the sales price determined by manufacturer $\mathrm{B}$.

(xii) $D_{1}$ is the sales quantity of manufacturer A during the given sales period, $D_{1}=\lambda a-\delta p_{1}+\theta p_{2}+\alpha \tau_{1}-\beta \tau_{2}$.

(xiii) $D_{2}$ is the sales quantity of manufacturer $\mathrm{B}$ during the given sales period, $D_{2}=(1-\lambda) a-\delta p_{2}+\theta p_{1}+$ $\alpha \tau_{2}-\beta \tau_{1}$.

(xiv) $R_{1}$ is the total revenue of the manufacturer $\mathrm{A}$.

(xv) $R_{2}$ is the total revenue of the manufacturer $\mathrm{B}$.

(xvi) $E$ is the benefit function of environment.

(xvii) $k$ is the per-unit energy-saving subsidy given by the government, $k>0$.

Some explanations are given for the above formulae. In almost all the related literature, the threshold value of the energy-saving level is always a constant. Thus, the energysaving level in this paper can be regarded as the value of which the energy-saving level is determined by one manufacturer minus the threshold value. In addition, following Hafezalkotob [9], we think that the energysaving level of one manufacturer will also affect the sales quantity of the other manufacturer; thus demand functions have two items both for the price and for the energysaving level. 
Without loss of generality, we assume that manufacturer $\mathrm{A}$ attracts more purchasing preference; i.e., $\lambda>1 / 2$. It is acknowledged that one channel's price effect is greater than the cross-price effect; namely, $\delta>\theta$. Furthermore, similar to the assumptions of Li et al. [8] and Hafezalkotob [9] with regard to the relationships of coefficients of the demand function, we assume that $\delta>\theta>\alpha>\beta$. Generally speaking, the market demand is more sensitive to price than to energy-saving levels, which is reasonable and is usually the case [4].

Following Ghosh and Shah [20] and Li et al. [8], the extra cost for manufacturer A (or B) to produce the green products is denoted by

$$
\frac{1}{2} \varphi \tau_{1}^{2}\left(\text { or } \frac{1}{2} \varphi \tau_{2}^{2}\right)
$$

For the free competitive case, the total revenue of the manufacturer $\mathrm{A}$ is

$$
R_{1}=\left(\lambda a-\delta p_{1}+\theta p_{2}+\alpha \tau_{1}-\beta \tau_{2}\right) p_{1}-\frac{1}{2} \varphi \tau_{1}^{2} .
$$

And the total revenue of the manufacturer $B$ is

$$
R_{2}=\left[(1-\lambda) a-\delta p_{2}+\theta p_{1}+\alpha \tau_{2}-\beta \tau_{1}\right] p_{2}-\frac{1}{2} \varphi \tau_{2}^{2} .
$$

For the case which involves energy-saving subsidy, $R_{1}^{\prime}=$ $R_{1}+k \tau_{1}$ and $R_{2}^{\prime}=R_{2}+k \tau_{2}$.

Besides, we formulate the benefit function of environment $E$ based on the sales quantity and the energy-saving level, just like the handling of Atasu and Souza [21]:

$$
\begin{aligned}
E= & \left(\lambda a-\delta p_{1}+\theta p_{2}+\alpha \tau_{1}-\beta \tau_{2}\right) \tau_{1} \\
& +\left[(1-\lambda) a-\delta p_{2}+\theta p_{1}+\alpha \tau_{2}-\beta \tau_{1}\right] \tau_{2} .
\end{aligned}
$$

For the sake of the following study, some premises are given as follows:

(1) This paper only considers substitutable and energysaving products produced and sold by duopolistic manufacturers, without any other competitor.

(2) Duopolistic manufacturers and the government are able to acquire complete information about the market and the revenue function.

(3) In order to avoid redundant discussions on the relationships of coefficients, we assume that $\varphi \geq \alpha$. In other words, we only consider cases that meet this inequality. In fact, a lot of papers with regard to green supply chains like Swami and Shah [1], Li et al. [8], and Javadi et al. [15] all adopt this practical constraint in their assumptions or in their case studies. In the next section, we will prove that this inequality is a sufficient condition to guarantee the existence and the uniqueness of the solution in the competitive case.

(4) Different demand rate seriously affects the stockholding cost, yet this paper only considers demand quantity instead of demand rate. Hence, we assume that the stock-holding cost is a constant, so that it does not affect the decision of each participant.

\section{Free Competition Model}

This section conducts a Bertrand game to examine how the two manufacturers make decisions on the prices and on the energy-saving levels. The existence and the uniqueness of each solution are demonstrated, and the change rate of the benefit function of environment with regard to purchasing preference proportions is examined.

Objective function (2) and objective function (3) compose a Bertrand game. In this game, both of the two participants have two decision variables: the sales price and the energy-saving level. In order to analyze the equilibrium solution of the game, we separately examine the two objective functions.

The following equation set is obtained by differentiating function (2):

$$
\left\{\begin{array}{l}
\frac{\partial R_{1}}{\partial p_{1}}=-2 \delta p_{1}+\lambda a+\theta p_{2}+\alpha \tau_{1}-\beta \tau_{2}=0 \\
\frac{\partial R_{1}}{\partial \tau_{1}}=\alpha p_{1}-\varphi \tau_{1}=0
\end{array}\right.
$$

Treating $\tau_{2}$ and $p_{2}$ as known, we examine the Hessian matrix $H_{1}$ of $R_{1}$ :

$$
H_{1}=\left[\begin{array}{cc}
-2 \delta & \alpha \\
\alpha & -\varphi
\end{array}\right]
$$

Apparently, $H_{1}$ is negative definite. Hence, the solution of equation set (5) is also the solution of $\max R_{1}$.

Similarly, the corresponding equation set with regard to $R_{2}$ is obtained:

$$
\left\{\begin{array}{l}
\frac{\partial R_{2}}{\partial p_{2}}=-2 \delta p_{2}+(1-\lambda) a+\theta p_{1}+\alpha \tau_{2}-\beta \tau_{1}=0 \\
\frac{\partial R_{2}}{\partial \tau_{2}}=\alpha p_{2}-\varphi \tau_{2}=0 .
\end{array}\right.
$$
$R_{2}$,

Regarding $\tau_{1}$ and $p_{1}$ as known, the Hessian matrix $H_{2}$ of

$$
H_{2}=\left[\begin{array}{cc}
-2 \delta & \alpha \\
\alpha & -\varphi
\end{array}\right]
$$

is also negative definite. Thus, the solution of equation set (7) is also the solution of $\max R_{2}$.

Given the above, the equilibrium solution of the considered game must meet equation set (5) and equation set (7) simultaneously.

By equation set (5) and equation set (7), $\tau_{1}$ and $\tau_{2}$ are expressed as follows:

$$
\left\{\begin{array}{l}
\tau_{1}=\frac{\alpha}{\varphi} p_{1} \\
\tau_{2}=\frac{\alpha}{\varphi} p_{2}
\end{array}\right.
$$

Thus, the following equations are obtained: 


$$
\begin{array}{r}
\left(\frac{\alpha^{2}}{\varphi}-2 \delta\right) p_{1}+\left(\theta-\frac{\alpha \beta}{\varphi}\right) p_{2}+\lambda a=0 \\
\left(\theta-\frac{\alpha \beta}{\varphi}\right) p_{1}+\left(\frac{\alpha^{2}}{\varphi}-2 \delta\right) p_{2}+(1-\lambda) a=0 .
\end{array}
$$

Because $\varphi \geq \alpha$ and $\delta>\alpha$, we have

$$
2 \delta \varphi-\alpha^{2}>\alpha^{2}>0
$$

By transforming (10), $p_{1}$ is expressed as follows:

$$
p_{1}=\frac{\theta \varphi-\alpha \beta}{2 \delta \varphi-\alpha^{2}} p_{2}+\frac{\lambda \varphi a}{2 \delta \varphi-\alpha^{2}} \text {. }
$$

By $\varphi \geq \alpha$ and $\delta>\theta>\alpha>\beta$, we have

$$
\begin{aligned}
& 2 \delta \varphi-\alpha^{2}-(\theta \varphi-\alpha \beta)>\delta \varphi-\alpha^{2}+\alpha \beta>\alpha \beta>0, \\
& 2 \delta \varphi-\alpha^{2}+\theta \varphi-\alpha \beta>\alpha^{2}>0 .
\end{aligned}
$$

Hence,

$$
\left(2 \delta \varphi-\alpha^{2}\right)^{2}-(\theta \varphi-\alpha \beta)^{2}>0
$$

We use "*" to denote solutions of variables. By dealing with formula (13) and (11), $p_{2}^{*}$ is then acquired as follows:

$$
p_{2}^{*}=\frac{(\theta \varphi-\alpha \beta) \lambda \varphi a+\left(2 \delta \varphi-\alpha^{2}\right)(1-\lambda) \varphi a}{\left(2 \delta \varphi-\alpha^{2}\right)^{2}-(\theta \varphi-\alpha \beta)^{2}} .
$$

Substituting expression (16) into formula (13), $p_{1}^{*}$ is obtained:

$$
p_{1}^{*}=\frac{\left(2 \delta \varphi-\alpha^{2}\right) \lambda \varphi a+(\theta \varphi-\alpha \beta)(1-\lambda) \varphi a}{\left(2 \delta \varphi-\alpha^{2}\right)^{2}-(\theta \varphi-\alpha \beta)^{2}} .
$$

Accordingly, $\tau_{1}^{*}$ and $\tau_{2}^{*}$ are obtained as follows:

$$
\left\{\begin{array}{l}
\tau_{1}^{*}=\frac{\left(2 \delta \varphi-\alpha^{2}\right) \lambda \alpha a+(\theta \varphi-\alpha \beta)(1-\lambda) \alpha a}{\left(2 \delta \varphi-\alpha^{2}\right)^{2}-(\theta \varphi-\alpha \beta)^{2}}, \\
\tau_{2}^{*}=\frac{(\theta \varphi-\alpha \beta) \lambda \alpha a+\left(2 \delta \varphi-\alpha^{2}\right)(1-\lambda) \alpha a}{\left(2 \delta \varphi-\alpha^{2}\right)^{2}-(\theta \varphi-\alpha \beta)^{2}} .
\end{array}\right.
$$

Thus, the optimal production quantities of the two manufacturers are obtained as follows:

$$
\left\{\begin{array}{l}
D_{1}^{*}=\frac{\left(2 \delta \varphi-\alpha^{2}\right) \lambda \delta \varphi a+(\theta \varphi-\alpha \beta)(1-\lambda) \delta \varphi a}{\left(2 \delta \varphi-\alpha^{2}\right)^{2}-(\theta \varphi-\alpha \beta)^{2}}, \\
D_{2}^{*}=\frac{(\theta \varphi-\alpha \beta) \lambda \delta \varphi a+\left(2 \delta \varphi-\alpha^{2}\right)(1-\lambda) \delta \varphi a}{\left(2 \delta \varphi-\alpha^{2}\right)^{2}-(\theta \varphi-\alpha \beta)^{2}} .
\end{array}\right.
$$

Clearly, all the solutions are unique under $\varphi \geq \alpha$. Thus, we draw the following conclusion.

Proposition 1. $\varphi \geq \alpha$ is a sufficient condition to guarantee the existence and the uniqueness of the equilibrium solution, where the comparison is under the background of getting rid of the unit of measurement.

Substituting the above solutions into formula (2), the maximum revenue of the manufacturer $\mathrm{A}$ is obtained:

$$
R_{1}^{*}=\left[\frac{\left(2 \delta \varphi-\alpha^{2}\right) \lambda+(\theta \varphi-\alpha \beta)(1-\lambda)}{\left(2 \delta \varphi-\alpha^{2}\right)^{2}-(\theta \varphi-\alpha \beta)^{2}}\right]^{2}\left(\delta \varphi^{2}-\frac{1}{2} \alpha^{2} \varphi\right) a^{2}
$$

And the maximum revenue of the manufacturer $B$ is

$$
R_{2}^{*}=\left(\frac{(\theta \varphi-\alpha \beta) \lambda+\left(2 \delta \varphi-\alpha^{2}\right)(1-\lambda)}{\left(2 \delta \varphi-\alpha^{2}\right)^{2}-(\theta \varphi-\alpha \beta)^{2}}\right)^{2}\left(\delta \varphi^{2}-\frac{1}{2} \alpha^{2} \varphi\right) a^{2} .
$$

Next, we consider the benefit function of environment in the competitive situation. By substituting all the acquired solutions into formula (4), we have

$$
\begin{aligned}
E^{*} & =\left(\lambda a-\delta p_{1}+\theta p_{2}+\alpha \tau_{1}-\beta \tau_{2}\right) \tau_{1}+\left[(1-\lambda) a-\delta p_{2}+\theta p_{1}+\alpha \tau_{2}-\beta \tau_{1}\right] \tau_{2} \\
& =\left[\frac{\left.\left(2 \delta \varphi-\alpha^{2}\right) \lambda+(\theta \varphi-\alpha \beta)(1-\lambda)\right]^{2}}{\left(2 \delta \varphi-\alpha^{2}\right)^{2}-(\theta \varphi-\alpha \beta)^{2}}\right]^{2} \alpha \varphi a^{2}+\left[\frac{(\theta \varphi-\alpha \beta) \lambda+\left(2 \delta \varphi-\alpha^{2}\right)(1-\lambda)}{\left(2 \delta \varphi-\alpha^{2}\right)^{2}-(\theta \varphi-\alpha \beta)^{2}}\right]^{2} \delta \alpha \varphi a^{2} \\
& =\frac{\left[\left(2 \delta \varphi-\alpha^{2}\right)^{2}+(\theta \varphi-\alpha \beta)^{2}\right]\left[\lambda^{2}+(1-\lambda)^{2}\right]+4\left(2 \delta \varphi-\alpha^{2}\right)(\theta \varphi-\alpha \beta)(1-\lambda) \lambda}{\left[\left(2 \delta \varphi-\alpha^{2}\right)^{2}-(\theta \varphi-\alpha \beta)^{2}\right]^{2}} \delta \alpha \varphi a^{2} .
\end{aligned}
$$


Under the circumstance that $\delta, \theta, \alpha, \beta$, and $\varphi$ are fixed, we briefly analyze the change of $E$ with regard to $\lambda$. The firstorder derivative of $E^{*}$ is obtained as follows:

$$
\begin{aligned}
\frac{\partial E^{*}}{\partial \lambda} & =\frac{\left[\left(2 \delta \varphi-\alpha^{2}\right)^{2}+(\theta \varphi-\alpha \beta)^{2}\right](4 \lambda-2)+4\left(2 \delta \varphi-\alpha^{2}\right)(\theta \varphi-\alpha \beta)(1-2 \lambda)}{\left[\left(2 \delta \varphi-\alpha^{2}\right)^{2}-(\theta \varphi-\alpha \beta)^{2}\right]^{2}} \delta \alpha \varphi a^{2} \\
& =\frac{\left[\left(2 \delta \varphi-\alpha^{2}\right)^{2}+(\theta \varphi-\alpha \beta)^{2}\right](4 \lambda-2)+2\left(2 \delta \varphi-\alpha^{2}\right)(\theta \varphi-\alpha \beta)(2-4 \lambda)}{\left[\left(2 \delta \varphi-\alpha^{2}\right)^{2}-(\theta \varphi-\alpha \beta)^{2}\right]^{2}} \delta \alpha \varphi a^{2} \\
& =\frac{\left[\left(2 \delta \varphi-\alpha^{2}\right)^{2}+(\theta \varphi-\alpha \beta)^{2}-2\left(2 \delta \varphi-\alpha^{2}\right)(\theta \varphi-\alpha \beta)\right]^{2}(4 \lambda-2)}{\left[\left(2 \delta \varphi-\alpha^{2}\right)^{2}-(\theta \varphi-\alpha \beta)^{2}\right]^{2}} \delta \alpha \varphi a^{2} \\
& =\frac{\left[\left(2 \delta \varphi-\alpha^{2}\right)-(\theta \varphi-\alpha \beta)\right]^{2}(4 \lambda-2)}{\left[\left(2 \delta \varphi-\alpha^{2}\right)^{2}-(\theta \varphi-\alpha \beta)^{2}\right]^{2}} \delta \alpha \varphi a^{2} .
\end{aligned}
$$

By $\lambda>1 / 2$, we know that the first-order derivative of $E$ is positive, which implies that $E$ is larger when $\lambda$ is more far away from $1 / 2$.

\section{Model with Energy-Saving Subsidies}

This section considers the competition case in which the government provides energy-saving subsidies for the energysaving production. In fact, the problem discussed in this section is formulated as a two-layer model: the government determines an energy-saving subsidy first, and then the two manufacturers declare their sales prices and energy-saving levels. We aim to analyze all the changes in sales prices, sales quantities, energysaving levels, and the energy benefit of environment.

The following equation set is obtained by differentiating $R_{1}^{\prime}$ :

$$
\left\{\begin{array}{l}
\frac{\partial R_{1}^{\prime}}{\partial p_{1}}=-2 \delta p_{1}+\lambda a+\theta p_{2}+\alpha \tau_{1}-\beta \tau_{2}=0 \\
\frac{\partial R_{1}^{\prime}}{\partial \tau_{1}}=\alpha p_{1}-\varphi \tau_{1}+k=0 .
\end{array}\right.
$$

The Hessian matrix $H_{1}^{\prime}$ of $R_{1}^{\prime}$ is the same as $H_{1}$. Hence, the solution of equation set (24) is also the solution of $\max R_{1}^{\prime}$.

The corresponding equation set with regard to $R_{2}^{\prime}$ is

$$
\left\{\begin{array}{l}
\frac{\partial R_{2}^{\prime}}{\partial p_{2}}=-2 \delta p_{2}+(1-\lambda) a+\theta p_{1}+\alpha \tau_{2}-\beta \tau_{1}=0 \\
\frac{\partial R_{2}^{\prime}}{\partial \tau_{2}}=\alpha p_{2}-\varphi \tau_{2}=0 .
\end{array}\right.
$$

Similarly, the solution of equation set (25) is also the solution of $\max R_{2}^{\prime}$.

Hence, the equilibrium solution must meet equation set (24) and equation set (25) simultaneously. By the elimination method, $\tau_{1}$ and $\tau_{2}$ are expressed as follows:

$$
\left\{\begin{array}{l}
\tau_{1}=\frac{\alpha p_{1}+k}{\varphi} \\
\tau_{2}=\frac{\alpha p_{2}+k}{\varphi}
\end{array}\right.
$$

Thus, the following equations are obtained:

$$
\begin{aligned}
& \left(\frac{\alpha^{2}}{\varphi}-2 \delta\right) p_{1}+\left(\theta-\frac{\alpha \beta}{\varphi}\right) p_{2}+\lambda a+\frac{\alpha k}{\varphi}-\frac{\beta k}{\varphi}=0 \\
& \left(\theta-\frac{\alpha \beta}{\varphi}\right) p_{1}+\left(\frac{\alpha^{2}}{\varphi}-2 \delta\right) p_{2}+(1-\lambda) a+\frac{\alpha k}{\varphi}-\frac{\beta k}{\varphi}=0
\end{aligned}
$$

By transforming (27), $p_{1}$ is expressed as follows:

$$
p_{1}=\frac{\theta \varphi-\alpha \beta}{2 \delta \varphi-\alpha^{2}} p_{2}+\frac{\lambda \varphi a+\alpha k-\beta k}{2 \delta \varphi-\alpha^{2}} .
$$

Denoting $p_{1}^{\prime}$ and $p_{2}^{\prime}$ as the solution of (27) and (28), we obtain $p_{2}^{\prime}$ by substituting formula (29) into (28): 


$$
p_{2}^{\prime}=\frac{(\theta \varphi-\alpha \beta)(\lambda \varphi a+\alpha k-\beta k)+\left(2 \delta \varphi-\alpha^{2}\right)[(1-\lambda) \varphi a+\alpha k-\beta k]}{\left(2 \delta \varphi-\alpha^{2}\right)^{2}-(\theta \varphi-\alpha \beta)^{2}}
$$

And $p_{1}^{\prime}$ is acquired by formulae (29) and (30):

$$
p_{1}^{\prime}=\frac{\left(2 \delta \varphi-\alpha^{2}\right)(\lambda \varphi a+\alpha k-\beta k)+(\theta \varphi-\alpha \beta)[(1-\lambda) \varphi a+\alpha k-\beta k]}{\left(2 \delta \varphi-\alpha^{2}\right)^{2}-(\theta \varphi-\alpha \beta)^{2}} .
$$

Accordingly, $\tau_{1}^{\prime}$ and $\tau_{2}^{\prime}$ are obtained as follows:

$$
\left\{\begin{array}{l}
\tau_{1}^{\prime}=\frac{k}{\varphi}+\frac{\alpha\left(2 \delta \varphi-\alpha^{2}\right)(\lambda \varphi a+\alpha k-\beta k)+\alpha(\theta \varphi-\alpha \beta)[(1-\lambda) \varphi a+\alpha k-\beta k]}{\varphi\left[\left(2 \delta \varphi-\alpha^{2}\right)^{2}-(\theta \varphi-\alpha \beta)^{2}\right]}, \\
\tau_{2}^{\prime}=\frac{k}{\varphi}+\frac{\alpha(\theta \varphi-\alpha \beta)(\lambda \varphi a+\alpha k-\beta k)+\alpha\left(2 \delta \varphi-\alpha^{2}\right)[(1-\lambda) \varphi a+\alpha k-\beta k]}{\varphi\left[\left(2 \delta \varphi-\alpha^{2}\right)^{2}-(\theta \varphi-\alpha \beta)^{2}\right]} .
\end{array}\right.
$$

In this case, involving energy-saving subsidies, the optimal production quantities of the two manufacturers are

$$
\left\{\begin{array}{l}
D_{1}^{\prime}=\frac{\delta\left(2 \delta \varphi-\alpha^{2}\right)(\lambda \varphi a+\alpha k-\beta k)+\delta(\theta \varphi-\alpha \beta)[(1-\lambda) \varphi a+\alpha k-\beta k]}{\left(2 \delta \varphi-\alpha^{2}\right)^{2}-(\theta \varphi-\alpha \beta)^{2}}, \\
D_{2}^{\prime}=\frac{\delta(\theta \varphi-\alpha \beta)(\lambda \varphi a+\alpha k-\beta k)+\delta\left(2 \delta \varphi-\alpha^{2}\right)[(1-\lambda) \varphi a+\alpha k-\beta k]}{\left(2 \delta \varphi-\alpha^{2}\right)^{2}-(\theta \varphi-\alpha \beta)^{2}} .
\end{array}\right.
$$

Apparently, in this situation, $\varphi \geq \alpha$ is still a sufficient condition to guarantee the existence and the uniqueness of the equilibrium solution.

Next, all the solutions of the two cases are compared.

Because $\alpha>\beta$ and $k>0$, we have

$$
p_{1}^{\prime}-p_{1}^{*}=p_{2}^{\prime}-p_{2}^{*}=\frac{\left(2 \delta \varphi-\alpha^{2}+\theta \varphi-\alpha \beta\right)(\alpha k-\beta k)}{\left(2 \delta \varphi-\alpha^{2}\right)^{2}-(\theta \varphi-\alpha \beta)^{2}}>0,
$$

which means that sales prices of both of the two manufacturers are higher when energy-saving subsidies exist. In reality, people always think that sales prices are lower when the government offers subsidies. The above conclusion is counterintuitive from this perspective.

Similarly,

$$
\tau_{1}^{\prime}-\tau_{1}^{*}=\tau_{2}^{\prime}-\tau_{2}^{*}=\frac{k}{\varphi}+\frac{\left(2 \delta \alpha \varphi-\alpha^{3}+\theta \alpha \varphi-\alpha^{2} \beta\right)(\alpha k-\beta k)}{\varphi\left[\left(2 \delta \varphi-\alpha^{2}\right)^{2}-(\theta \varphi-\alpha \beta)^{2}\right]}>0 .
$$

Given the above, we draw the conclusion that both of the two manufacturers will enhance their energy-saving levels to counteract the impact incurred by the rise on sales prices. The result that the optimal sales price is higher in the presence of energy-saving incentive is contrary to the intuition.

Apparently, the maximum revenue of the two manufacturers will be significantly increased by energy-saving incentive. In practice, manufacturers who produce electrical appliances are more positive in the presence of energysaving subsidies offered by the government.

Next, we analyze the change rate of $E$ with regard to $k$ to provide theoretical foundations for the government to make policies of energy-saving incentive. 
By substituting all the acquired solutions into formula

(4), we have

$$
\begin{aligned}
E^{\prime}= & \frac{\delta k\left(2 \delta \varphi-\alpha^{2}+\theta \varphi-\alpha \beta\right)(\varphi a+2 \alpha k-2 \beta k)}{\varphi\left[\left(2 \delta \varphi-\alpha^{2}\right)^{2}-(\theta \varphi-\alpha \beta)^{2}\right]}+\frac{\left[\left(2 \delta \varphi-\alpha^{2}\right)^{2}+(\theta \varphi-\alpha \beta)^{2}\right](\varphi a+2 \alpha k-2 \beta k) \delta \alpha}{\left[\left(2 \delta \varphi-\alpha^{2}\right)^{2}-(\theta \varphi-\alpha \beta)^{2}\right] \varphi} \\
& +\frac{4\left(2 \delta \varphi-\alpha^{2}\right)(\theta \varphi-\alpha \beta)(\lambda \varphi a+\alpha k-\beta k)[(1-\lambda) \varphi a+\alpha k-\beta k] \delta \alpha}{\left[\left(2 \delta \varphi-\alpha^{2}\right)^{2}-(\theta \varphi-\alpha \beta)^{2}\right] \varphi} .
\end{aligned}
$$

In this case, we regard $\lambda$ as fixed. The first-order derivative of $E^{\prime}$ with regard to $k$ is obtained as follows:

$$
\begin{aligned}
\frac{\partial E^{\prime}}{\partial k}= & \frac{\left(2 \delta \varphi-\alpha^{2}+\theta \varphi-\alpha \beta\right)(\delta \varphi a+4 \delta \alpha k-4 \delta \beta k)}{\varphi\left[\left(2 \delta \varphi-\alpha^{2}\right)^{2}-(\theta \varphi-\alpha \beta)^{2}\right]}+\frac{\left[\left(2 \delta \varphi-\alpha^{2}\right)^{2}+(\theta \varphi-\alpha \beta)^{2}\right](2 \alpha-2 \beta) \delta \alpha}{\left[\left(2 \delta \varphi-\alpha^{2}\right)^{2}-(\theta \varphi-\alpha \beta)^{2}\right] \varphi} \\
& +\frac{4\left(2 \delta \varphi-\alpha^{2}\right)(\theta \varphi-\alpha \beta)(\alpha-\beta)[\varphi a+2 \alpha k-2 \beta k] \delta \alpha}{\left[\left(2 \delta \varphi-\alpha^{2}\right)^{2}-(\theta \varphi-\alpha \beta)^{2}\right] \varphi} .
\end{aligned}
$$

Clearly, the first-order derivative of $E$ ' is positive under $k>0, \varphi \geq \alpha$, and $\delta>\theta>\alpha>\beta$. Hence, in order to enhance the environment benefit, the government should maximize the per-unit energy-saving subsidy as possible within the scope of its budget.

Considering a financial budget $g$, we present the following model to determine the maximal value of $k$ so as to maximize $E^{\prime}$ :

$$
\begin{aligned}
& \max k \\
& \text { s.t. } \quad \tau_{1}^{\prime} k+\tau_{2}^{\prime} k \leq g .
\end{aligned}
$$

By (32), we know that the constraint of model (38) is a quadratic inequality with a negative quadratic term, which means that the quadratic formula is adopted to acquire the maximum value of $k$.

\section{A Numerical Illustration on Brick Production}

Before illustrating the performance of the developed models, let us have a look at the government policies in energysaving production. Although the entity enterprises substantially contribute to the gross domestic product (GDP) in many developing countries, they often utilize outdated, energy-intensive technologies to carry out industrial production activities [9], which lead to serious pollution on environment.

The promotion of energy-saving production is one important aspect to lower electricity consumption and oil consumption. Hence, the government pays much attention to strengthen the awareness of energy saving. In China, for example, the government provides energy-saving subsidies for many electrical and petrolic appliances. Both manufacturers and consumers benefit from this energy-saving policy.
In order to visualize the models and make some supplements, we first consider the following scenario without energy-saving incentive: market potential $a=2000$, consumers' purchasing preference proportions for manufacturer $\mathrm{A}$ and manufacturer $\mathrm{B}$ are 0.6 and 0.4 , the marginal demand with respect to the sales price $\delta=4$, the demand shift with respect to the price $\theta=3$, the marginal demand with respect to the energy-saving level $\alpha=2$, the demand shift with respect to the energy-saving level $\beta=1$, and the fixed cost related to the energy-saving level $\varphi=2$. Apparently, all the given parameters meet the constraints raised in Section 2.

By formula (16) and formula (17), we have $p_{1}^{*}=275$ and $p_{2}^{*}=225$. Accordingly, $\tau_{1}^{*}$ and $\tau_{2}^{*}$ are obtained by formula (18): $\tau_{1}^{*}=275$ and $\tau_{2}^{*}=225$. By functions of sales quantity, we have $D_{1}^{*}=1100$ and $D_{2}^{*}=900$. In addition, the maximum revenue of manufacturer $A$ and manufacturer $B$ is $R_{1}^{*}=226875$ and $R_{2}^{*}=151875$, respectively. The benefit of environment $E^{*}=505000$.

Under other parameters which remain fixed, we analyze the derivative of $E$ with regard to $\lambda$. The first-order derivative of $E^{*}$ is

$$
\frac{\partial E^{*}}{\partial \lambda}=500000(2 \lambda-1) .
$$

Therefore, the impact of the difference of purchasing preference proportions is shown.

Next, we investigate the issue that how the government determines the per-unit energy-saving subsidy under a finite financial budget constraint. We assume that the financial budget of the government is 150000; namely,

$$
k \tau_{1}^{\prime}+k \tau_{2}^{\prime} \leq 150000
$$


Because solutions in Section 4 are all unique, we know that $\tau_{1}^{\prime}$ and $\tau_{2}^{\prime}$ are determined by formula (32) under any perunit energy-saving subsidy $k$. By substituting all the parameters, we consider the following programming:

$\max k$

$$
\begin{array}{ll}
\text { s.t. } & \frac{10}{8} k^{2}+500 k \leq 150000 \\
& k \geq 0 .
\end{array}
$$

Solving the quadratic inequality in the constraint, we have $0 \leq k \leq 200$. Hence, $\max k=200$. Accordingly, optimal sales prices and optimal energy-saving levels of the two manufacturers are determined by acquired formulae (30) and (31): $p_{1}^{\prime}=300$ and $p_{2}^{\prime}=250$. By (32), the energy-saving level of each manufacturer is obtained as follows: $\tau_{1}^{\prime}=400>\tau_{1}^{*}$ and $\tau_{2}^{\prime}=350>\tau_{2}^{*}$. Clearly, all the results coincide with the drawn conclusions in the previous section.

\section{Conclusions}

In this paper, we investigate production and pricing issues of energy-saving products in the presence of duopolistic manufacturers. Both a free competition case and a two-layer case under production subsidies are analyzed. A sufficient condition is proposed to guarantee the existence and the uniqueness of the equilibrium solution for each case. Sensitivities of the benefit function of environment with regard to purchasing preference proportions and energy-saving subsidies are examined. The problem of how to effectively utilize a finite financial budget for stimulating energy-saving production is discussed at the point of view of the government.

Nevertheless, our models and methods have some shortcomings. We only consider the different purchase preference for each product, but the degree of the substitutability between the two products has not been considered. Demand functions should be modified when taking the substitutability into account. In addition, the government always takes both the environment benefit and the financial budget into consideration in practice. In this situation, we should improve the model by trading off the two conflicting goals.

\section{Data Availability}

The data used to support the findings of this study are included within the article.

\section{Conflicts of Interest}

The authors declare that there are no conflicts of interest regarding the publication of this paper.

\section{References}

[1] S. Swami and J. Shah, "Channel coordination in green supply chain management," Journal of the Operational Research Society, vol. 64, no. 3, pp. 336-351, 2013.
[2] S. Asian, A. Hafezalkotob, and J. J. John, "Sharing economy in organic food supply chains: a pathway to sustainable development," International Journal of Production Economics, vol. 218, pp. 322-338, 2019.

[3] G. Xie, W. Y. Yue, W. R. Liu, and S. Y. Wang, "Risk based selection of cleaner products in a green supply chain," Pacific Journal of Optimization, vol. 8, no. 3, pp. 473-484, 2012.

[4] G. Xie, "Modeling decision processes of a green supply chain with regulation on energy saving level," Computers \& Operations Research, vol. 54, pp. 266-273, 2015.

[5] J. Ke, L. Price, S. Ohshita et al., "China's industrial energy consumption trends and impacts of the top-1000 enterprises energy-saving program and the ten key energy-saving projects," Energy Policy, vol. 50, pp. 562-569, 2012.

[6] Q. Zhang, W. Tang, and J. Zhang, "Green supply chain performance with cost learning and operational inefficiency effects," Journal of Cleaner Production, vol. 112, no. 4, pp. 3267-3284, 2016.

[7] Y. Arda, "Managing new and remanufactured products to mitigate environmental damage under emissions regulation," European Journal of Operational Research, vol. 249, no. 1, pp. 117-130, 2016.

[8] B. Li, M. Zhu, Y. Jiang, and Z. Li, "Pricing policies of a competitive dual-channel green supply chain," Journal of Cleaner Production, vol. 112, no. 3, pp. 2029-2042, 2016.

[9] A. Hafezalkotob, "Competition, cooperation, and coopetition of green supply chains under regulations on energy saving levels," Transportation Research Part E: Logistics and Transportation Review, vol. 97, pp. 228-250, 2017.

[10] H. Song and X. Gao, "Green supply chain game model and analysis under revenue-sharing contract," Journal of Cleaner Production, vol. 170, no. 3, pp. 183-192, 2018.

[11] Z. Lu and S. Shao, "Impacts of government subsidies on pricing and performance level choice in energy performance contracting: a two-step optimal decision model," Applied Energy, vol. 184, pp. 1176-1183, 2016.

[12] I. E. Nielsen, S. Majumder, and S. Saha, "Game-theoretic analysis to examine how government subsidy policies affect a closed-loop supply chain decision," Applied Sciences, vol. 10, no. 1, p. 145, 2019.

[13] I.-H. Hong, P.-C. Chen, and H.-T. Yu, "The effects of government subsidies on decentralised reverse supply chains," International Journal of Production Research, vol. 54, no. 13, pp. 3962-3977, 2016.

[14] A. Hafezalkotob, "Modelling intervention policies of government in price-energy saving competition of green supply chains," Computers \& Industrial Engineering, vol. 119, pp. 247-261, 2018.

[15] T. Javadi, N. Alizadeh-Basban, S. Asian, and A. Hafezalkotob, "Pricing policies in a dual-channel supply chain considering flexible return and energy-saving regulations," Computers \& Industrial Engineering, vol. 135, pp. 655-674, 2019.

[16] S. Safarzadeh and M. Rasti-Barzoki, "A game theoretic approach for pricing policies in a duopolistic supply chain considering energy productivity, industrial rebound effect, and government policies," Energy, vol. 167, pp. 92-105, 2019.

[17] Z. Lou, X. Lou, and X. Dai, "Game-theoretic models of green products in a two-echelon dual-channel supply chain under government subsidies," Mathematical Problems in Engineering, vol. 2020, Article ID 2425401, 11 pages, 2020.

[18] S.-L. Yang and Y.-W. Zhou, "Two-echelon supply chain models: considering duopolistic retailers' different competitive behaviors," International Journal of Production Economics, vol. 103, no. 1, pp. 104-116, 2006. 
[19] N. M. Modak, S. Panda, and S. S. Sana, "Pricing policy and coordination for a two-layer supply chain of duopolistic retailers and socially responsible manufacturer," International Journal of Logistics Research and Applications, vol. 19, no. 6, pp. 487-508, 2016.

[20] D. Ghosh and J. Shah, "A comparative analysis of greening policies across supply chain structures," International Journal of Production Economics, vol. 135, no. 2, pp. 568-583, 2012.

[21] A. Atasu and G. C. Souza, "How does product recovery affect quality choice?" Production and Operations Management, vol. 22, no. 4, pp. 991-1010, 2013. 